\title{
0-1 Test for Chaos in a Fractional Order Financial System with Investment Incentive
}

\author{
Baogui Xin ${ }^{1,2}$ and Yuting $\mathrm{Li}^{1}$ \\ ${ }^{1}$ Nonlinear Science Center, School of Economics and Management, Shandong University of Science and Technology, \\ Qingdao 266590, China \\ ${ }^{2}$ Nonlinear Dynamics and Chaos Group, School of Management, Tianjin University, Tianjin 300072, China \\ Correspondence should be addressed to Baogui Xin; xin@tju.edu.cn
}

Received 5 September 2013; Accepted 25 September 2013

Academic Editor: Luca Guerrini

Copyright (C) 2013 B. Xin and Y. Li. This is an open access article distributed under the Creative Commons Attribution License, which permits unrestricted use, distribution, and reproduction in any medium, provided the original work is properly cited.

\begin{abstract}
A new integer-order chaotic financial system is extended by introducing a simple investment incentive into a three-dimensional chaotic financial system. A four-dimensional fractional-order chaotic financial system is presented by bringing fractional calculus into the new integer-order financial system. By using weighted integral thought, the fractional order derivative's economics meaning is given. The 0-1 test algorithm and the improved Adams-Bashforth-Moulton predictor-corrector scheme are employed to detect numerically the chaos in the proposed fractional order financial system.
\end{abstract}

\section{Introduction}

In recent years there has been a high level of interest in the study of chaotic economic systems $[1,2]$. Chaotic systems refer to nonlinear dynamical systems which are very sensitive to initial conditions, in a such way that a small perturbation of these could have unpredictable consequences on the evolution equations. As a complex system, the financial system shows a lot of nonlinear dynamical phenomena, such as chaos, fractals, and bifurcation. Reference [3] firstly presented a nonlinear financial model as follows:

$$
\begin{gathered}
\dot{x}=z+(y-a) x, \\
\dot{y}=1-b y-x^{2}, \\
\dot{z}=-x-c z,
\end{gathered}
$$

where $x$ denotes the interest rate, $y$ denotes the investment demand, $z$ denotes the price index, $a$ is the saving amount, $b$ is the cost per investment, $c$ is the demand elasticity of commercial markets, and all three constants $a, b, c \geq 0$.

References [4-7] analyzed some complex behavior of system (1), such as bifurcation and chaos. Reference [8] introduced fractional calculus into system (1) and studied its complex dynamics [9]. References [10, 11] studied chaos control of the fractional-order form of system (1). Reference [12] proposed an uncertain fractal-order form of system (1) and studied its chaos control via adaptive sliding mode. Reference [13] proposed an uncertain and stochastic form of system (1) with multiple delays. Reference [14] proposed a discrete form of system (1) and studied its Neimark-Sacker bifurcation. References $[15,16]$ presented a form of system (1) with time-delayed feedback and studied its dynamics and control. Reference [17] studied Hopf-pitchfork bifurcation and periodic phenomena in the system (1) with time delays. Reference [18] extended system (1) with the average profit margin.

Investment is an important economic activity [19]. In order to cope with high unemployment or backwardness, in many cases a government would use their policies to stimulate investment which will raise employment, exports, tax revenue, and so on. These incentives may take the form of investment grants or investment credit that reduces capital costs for investors. But these various forms of investment incentives also will arouse the investment demand of the financial system (1). In other words, there may be a positive feedback mechanism between investment command and investment incentive. Thus we can describe the above 
mechanism by using the following four-dimensional financial system with a simple investment incentive:

$$
\begin{gathered}
\dot{x}=z+(y-a) x, \\
\dot{y}=1-b y-x^{2}+u, \\
\dot{z}=-x-c z, \\
\dot{u}=d y,
\end{gathered}
$$

where $x, y, z, a, b$, and $c$ have the same meanings as those defined in the system (1), $u$ denotes the investment incentive, and $d \geq 0$ is the coefficient of investment incentive intensity.

Researchers' ever-growing interests in fractional calculus have led the ever-broadening applications in a lot of fields [20-25]. When fractional calculus is introduced into the system (2), its fractional-order form can be described with fractional derivative as follows:

$$
\begin{gathered}
\frac{d^{q_{1}} x}{d t^{q_{1}}}=z+(y-a) x, \\
\frac{d^{q_{2}} y}{d t^{q_{2}}}=1-b y-x^{2}+u, \\
\frac{d^{q_{3}} z}{d t^{q_{3}}}=-x-c z, \\
\frac{d^{q_{4}} u}{d t^{q_{4}}}=d y,
\end{gathered}
$$

in which $q=\left(q_{1}, q_{2}, q_{3}, q_{4}\right)$ is subject to $0<q_{1}, q_{2}, q_{3}, q_{4}<1$.

Remark 1. When $q=(1,1,1,1)$, the system (3) degenerates into the system (2).

The remainder of this paper is organized as follows. In Section 2, we give some preliminaries, such as Caputo fractional derivative's economics meaning, numerical solutions of the system (3), and the 0-1 test algorithm. In Section 3, we numerically illustrate the chaos existence of the proposed financial system by using the improved Adams-BashforthMoulton predictor-corrector scheme and 0-1 test algorithm. Finally conclusions in Section 4 close the paper.

\section{Preliminaries}

\subsection{Caputo Fractional Derivative and Its Economics Meaning}

2.1.1. Weighted Integral. The integer integral and derivative are very helpful to understand fractional integral and derivative. An integral can be thought of as an area or a generalization of area.

Definition 2. Given a weighted factor $f(x)$ and a function $g(x)$ for $a \leq x \leq b$, the definite weighted integral $\int_{a}^{b} f(x) g(x) d x$ is a real number whose geometrical interpretation is the signed area under the graph of weighted function $y=f(x) g(x)$ for $a \leq x \leq b$.

The Riemann integral is a simple and well-understood integral definition. If the continuous function $g(x)$ is defined on interval $[a, b]$ and a partition $P$ of $[a, b]$ can be divided into a collection of subintervals $\left[x_{0}, x_{1}\right],\left[x_{1}, x_{2}\right], \ldots,\left[x_{n-1}, x_{n}\right]$, for each $i=1,2, \ldots, n$, a point $x_{i}^{*}$ in $\left[x_{n-1}, x_{n}\right]$, and its weighted factor $f\left(x_{i}^{*}\right)$, weighted Riemann integral $\int_{a}^{b} f(x) g(x) d x$ can be rewritten as

$$
\int_{a}^{b} f(x) g(x) d x=\lim _{n \rightarrow \infty} \sum_{i=1}^{n} f\left(x_{i}^{*}\right) g\left(x_{i}^{*}\right) \Delta x_{i}
$$

for any choice of the $x_{i}^{*}$ in $\left[x_{n-1}, x_{n}\right]$ with $\Delta x=(b-a) / n$ and $x_{i}=a+i \Delta x$.

When $f(x)=1$, the weighted integral $\int_{a}^{b} f(x) g(x) d x=$ $\int_{a}^{b} g(x) d x$ completely degenerates into a common integral.

2.1.2. Caputo Fractional Derivative. Loosely speaking, a derivative can be interpreted as a kind of change ratio. More specifically it is the measure of infinitesimal change ratio of the output over the infinitesimal change of the input. For example, consider the following.

Definition 3. The first order derivative of function $f(t)$ with respect to $t$ is given by

$$
f^{\prime}(t)=\lim _{h \rightarrow 0} \frac{f(t+h)-f(t)}{h} .
$$

Definition 4. The 2 nd order derivative of function $f(t)$ with respect to $t$ is given by

$$
f^{\prime \prime}(t)=\lim _{h \rightarrow 0} \frac{f^{\prime}(t+h)-f^{\prime}(t)}{h} .
$$

Definition 5. The $m$ th order derivative of function $f(t)$ with respect to $t$ is given by

$$
\begin{aligned}
f^{(m)}(t) & =\lim _{h \rightarrow 0} \frac{f^{(m-1)}(t+h)-f^{(m-1)}(t)}{h} \\
& =\lim _{h \rightarrow 0} \frac{1}{h^{m}} \sum_{n=0}^{m}(-1)^{n}\left(\begin{array}{c}
m \\
n
\end{array}\right) f(t-n h) .
\end{aligned}
$$

And there are several definitions of fractional derivatives, roughly speaking, which can be thought of as generalized above derivatives. The Caputo definition is a common notation of fractional derivative. Briefly the Caputo fractional derivative is a kind of weighted change ratio in a time interval. More specifically, the Caputo fractional derivative can be considered as a kind of weighted integral of the integer order derivative of a function on an interval. In this paper, we will adopt the following Caputo definition.

Definition 6. The $q$ th order fractional derivative of function $f(t)$ with respect to $t$ is given by

$$
D_{a}^{q} f(t)=\int_{a}^{t} K_{q}(t-\tau) f^{(m)}(\tau) d \tau
$$

where $K_{q}(t-\tau)=(t-\tau)^{m-q-1} / \Gamma(m-q), \Gamma(m-q)=$ $\int_{0}^{\infty} \tau^{m-q-1} e^{-\tau} d \tau, t \in[a, b], m$ is an integer and $m-1<q \leq m$. 
The functions $f^{(m)}(t)$ in Definitions 5 and 6 are the same. When $K_{q}(t-\tau)$ is regarded as a kind of weight, then $D_{a}^{q} f(t)$ can be regarded as a kind of weighted integral with respect to $f^{(m)}(t)$. What is more, $f^{(m)}(t)$ can be regarded as $m$ th order change ratio of the function $f(t)$ at $t$; that is, there is no memory effect in $f^{(m)}(t)$. However, $D_{a}^{q} f(t)$ can be regarded as a weighted integral of the $m$ th order derivative of the function $f(t)$ on the whole interval $[a, b]$, and the weight $K_{q}(t-\tau)$ depends on the specific time; that is, there are memory effects in $D_{a}^{q} f(t)$.

2.1.3. Caputo Fractional Derivative's Economics Meaning. In economics, let me illustrate a concrete example like the system (3), for the investment demand function $y(t)$, its integer order derivative $y^{(m)}(t)$, and its fractional order derivative $D_{0}^{q} y(t), y^{(m)}(t)$ can be regarded as $m$ th order change ratio of the investment demand $y(t)$ at the time $t$; that is, it is unrelated to any time before the time $t$; that is, there is no memory effect in $y^{(m)}(t)$. However, $D_{0}^{q} y(t)$ can be regarded as a weighted integral of all $m$ th order derivative of the investment demand $y(t)$ on the whole time interval $[0, t]$; that is, $D_{0}^{q} y(t)$ does not only depend on the time $t$, but also depends on any time before the time $t$; that is, there are memory effects in $D_{0}^{q} y(t)$. In the system (3), $m=1$ and its memory effects are easier to be understood, so we will not repeat them here. In fact, a lot of economics variables have memory effects; for example, our past economic behavior may affect our present and future ones. In other research fields, there are also a lot of memory effects, such as psychological shadow, escalation of commitment, sunk cost effect, lazy battery effect, and shape memory effect. As mentioned above, there are some memory effects in financial systems, so the fractional derivative may be more suitable to study them.

2.2. Numerical Solutions of Fractional Order System. Based on the improved Adams-Bashforth-Moulton predictorcorrector scheme [26-29], one can solve fractional-order ordinary differential equations. The numerical calculation formula of fractional-order system (3) can be described as follows.

With the initial value $\left(x_{0}^{(k)}, y_{0}^{(k)}, z_{0}^{(k)}, u_{0}^{(k)}\right), k=0,1, \ldots$, $[m]-1$, and the fractional-order system (3) is equivalent to the Volterra integral equations as follows:

$$
\begin{aligned}
x(t)= & \sum_{k=0}^{[m]-1} x_{0}^{(k)} \frac{t^{k}}{k !}+\frac{1}{\Gamma\left(q_{1}\right)} \\
& \times \int_{0}^{t}(t-\tau)^{q_{1}-1}(z(\tau)+(y(\tau)-a) x(\tau)) d \tau, \\
y(t)= & \sum_{k=0}^{[m]-1} y_{0}^{(k)} \frac{t^{k}}{k !}+\frac{1}{\Gamma\left(q_{2}\right)} \\
& \times \int_{0}^{t}(t-\tau)^{q_{2}-1}\left(1-b y(\tau)-x^{2}(\tau)+u(\tau)\right) d \tau,
\end{aligned}
$$

$$
\begin{aligned}
z(t)= & \sum_{k=0}^{[m]-1} z_{0}^{(k)} \frac{t^{k}}{k !}+\frac{1}{\Gamma\left(q_{3}\right)} \\
& \times \int_{0}^{t}(t-\tau)^{q_{3}-1}(-x(\tau)-c z(\tau)) d \tau, \\
u(t)= & \sum_{k=0}^{[m]-1} u_{0}^{(k)} \frac{t^{k}}{k !}+\frac{1}{\Gamma\left(q_{4}\right)} \\
& \times \int_{0}^{t}(t-\tau)^{q_{4}-1} d y(\tau) d \tau .
\end{aligned}
$$

Let $h=T / N, t_{n}=n h, n=0,1, \ldots, N \in Z^{+}$, and the fractional-order system (3) can be approximated to the following difference equations:

$$
\begin{aligned}
x_{n+1}= & x_{0}+\frac{h^{q_{1}}}{\Gamma\left(q_{1}+2\right)} \\
& \times\left(z_{n+1}^{p}+\left(y_{n+1}^{p}-a\right) x_{n+1}^{p}\right)+\frac{h^{q_{1}}}{\Gamma\left(q_{1}+2\right)} \\
& \times \sum_{j=0}^{n} \alpha_{1, j, n+1}\left(z_{j}+\left(y_{j}-a\right) x_{j}\right), \\
y_{n+1}= & y_{0}+\frac{h^{q_{2}}}{\Gamma\left(q_{2}+2\right)} \\
& \times\left(1-b y_{n+1}^{p}-\left(x_{n+1}^{p}\right)^{2}+u_{n+1}^{p}\right)+\frac{h^{q_{2}}}{\Gamma\left(q_{2}+2\right)} \\
& \times \sum_{j=0}^{n} \alpha_{2, j, n+1}\left(1-b y_{j}-\left(x_{j}\right)^{2}+u_{j}\right), \\
z_{n+1}= & z_{0}+\frac{h^{q_{3}}}{\Gamma\left(q_{3}+2\right)} \\
& \times\left(-x_{n+1}^{p}-c z_{n+1}^{p}\right)+\frac{h^{q_{3}}}{\Gamma\left(q_{3}+2\right)} \\
& \times \sum_{j=0}^{n} \alpha_{3, j, n+1}\left(-x_{j}-c z_{j}\right), \\
u_{n+1}= & u_{0}+\frac{h^{q_{4}}}{\Gamma\left(q_{4}+2\right)}\left(d y_{n+1}^{p}\right)+\frac{h^{q_{4}}}{\Gamma\left(q_{4}+2\right)} \\
& \times \sum_{j=0}^{n} \alpha_{4, j, n+1}\left(d y_{j}\right), \\
&
\end{aligned}
$$

where

$$
\begin{aligned}
x_{n+1}^{p}= & x_{0}+\frac{1}{\Gamma\left(q_{1}\right)} \\
& \times \sum_{j=0}^{n} \beta_{1, j, n+1}\left(z_{j}+\left(y_{j}-a\right) x_{j}\right),
\end{aligned}
$$




$$
\begin{aligned}
& y_{n+1}^{p}=y_{0}+\frac{1}{\Gamma\left(q_{2}\right)} \\
& \times \sum_{j=0}^{n} \beta_{2, j, n+1}\left(1-b y_{j}-\left(x_{j}\right)^{2}+u_{j}\right), \\
& z_{n+1}^{p}=z_{0}+\frac{1}{\Gamma\left(q_{3}\right)} \sum_{j=0}^{n} \beta_{3, j, n+1}\left(-x_{j}-c z_{j}\right), \\
& u_{n+1}^{p}=u_{0}+\frac{1}{\Gamma\left(q_{4}\right)} \sum_{j=0}^{n} \beta_{4, j, n+1}\left(d y_{j}\right), \\
& \alpha_{i, j, n+1}=\left\{\begin{array}{cl}
n^{q_{i}+1}-\left(n-q_{i}\right)(n+1)^{q_{i},}, & j=0, \\
(n-j+2)^{q_{i}+1}+(n-j)^{q_{i}+1} & \\
-2(n-j+1)^{q_{i}+1}, & 1 \leq j \leq n, \\
& i=1,2,3,4, \\
1, & j=n+1,
\end{array}\right. \\
& \beta_{i, j, n+1}=\frac{h^{q_{i}}}{q_{i}}\left((n-j+1)^{q_{i}}-(n-j)^{q_{i}}\right), \\
& 0 \leq j \leq n, i=1,2,3,4 .
\end{aligned}
$$

Errors of the above method are

$$
\begin{aligned}
& \Delta x=\max _{j=0,1, \ldots, N}\left|x\left(t_{j}\right)-x_{h}\left(t_{j}\right)\right|=\mathcal{O}\left(h^{p_{1}}\right), \\
& \Delta y=\max _{j=0,1, \ldots, N}\left|y\left(t_{j}\right)-y_{h}\left(t_{j}\right)\right|=\mathcal{O}\left(h^{p_{2}}\right), \\
& \Delta z=\max _{j=0,1, \ldots, N}\left|z\left(t_{j}\right)-z_{h}\left(t_{j}\right)\right|=\mathcal{O}\left(h^{p_{3}}\right), \\
& \Delta u=\max _{j=0,1, \ldots, N}\left|u\left(t_{j}\right)-u_{h}\left(t_{j}\right)\right|=\mathcal{O}\left(h^{p_{4}}\right),
\end{aligned}
$$

where $p_{i}=\min \left(2,1+q_{i}\right)$.

2.3. The 0-1 Test Algorithm. There are many approaches to detect chaos, but 0-1 test is one of the simplest and most effective ones, which was proposed by Gottwald and Melbourne [30] and also has already been successfully tested for various discrete or continuous systems, such as [31-45].

In this section, we introduce the detailed steps of the 0 1 test algorithm to robustly distinguish regular from chaotic dynamics in deterministic continuous dynamical systems. In fact, one can directly implement the $0-1$ test algorithm if the given time series is generated from a discrete time system. But if the given time series is generated from a continuous time system, there may be a well-known oversampling issue that must overcome it. So the oversampling issue should be considered when we distinguish regular from chaotic dynamic system (3).

Consider a set of measurement data $\phi_{0}(i)$ obtained from a continuous time system, where $i=1,2, \ldots, T$, and $T$ is the amount of the data, the $0-1$ test algorithm can be described as follows.
Step 1. Rearrange the initial measurement data with an optimal sampling time.

The average mutual information [46] between $\phi_{0}(i)$ and $\phi_{0}(i+\tau)$ is defined as

$$
\begin{aligned}
I(\tau)= & \sum_{\phi_{0}(i), \phi_{0}(i+\tau)} P\left(\phi_{0}(i), \phi_{0}(i+\tau)\right) \\
& \times \log _{2}\left[\frac{P\left(\phi_{0}(i), \phi_{0}(i+\tau)\right)}{P\left(\phi_{0}(i)\right) P\left(\phi_{0}(i+\tau)\right)}\right],
\end{aligned}
$$

where $\tau$ is the time delay, that is, sampling time.

The value $\tau$ corresponding to the first local minimum of the mutual information $I(\tau)$ is the optimal sampling time. Thus we can rearrange the initial measurement data $\phi_{0}(i)$ into the finely sampled measurement data $\phi(j)$ in the following way:

$$
\phi(j)=\phi_{0}(i+j \tau),
$$

where $i=1,2, \ldots, T$, and $j=1,2,3, \ldots, N$.

Step 2. Choose a random number $c \in(\pi / 5,4 \pi / 5)$ and define the following new coordinates $\left(p_{c}(n), s_{c}(n)\right)$ :

$$
\begin{aligned}
& p_{c}(n)=\sum_{j=1}^{n} \phi(j) \cos (\theta(j)), \\
& s_{c}(n)=\sum_{j=1}^{n} \phi(j) \sin (\theta(j)),
\end{aligned}
$$

where

$$
\theta(j)=j c+\sum_{i=1}^{j} \phi(j), \quad j=1,2,3, \ldots, n .
$$

Step 3. Define the mean square displacement $M_{c}(n)$ as follows:

$$
\begin{aligned}
M_{c}(n)= & \lim _{N \rightarrow \infty} \frac{1}{N} \\
& \times \sum_{j=1}^{N}\left(p_{c}(j+n)-p_{c}(j)\right)^{2} \\
& +\left(s_{c}(j+n)-s_{c}(j)\right)^{2}, \quad n \in\left[1, \frac{N}{10}\right] .
\end{aligned}
$$

Step 4. Define the modified mean square displacement $D_{c}(n)$ as follows:

$$
D_{c}(n)=M_{c}(n)-\left(\lim _{N \rightarrow \infty} \frac{1}{N} \sum_{j=1}^{N} \phi(j)\right)^{2} \frac{1-\cos n c}{1-\cos c} .
$$

Step 5. Define the median value of correlation coefficient $K$ as follows:

$$
K=\operatorname{median}\left(K_{c}\right),
$$


where

$$
K_{c}=\frac{\operatorname{cov}(\xi, \Delta)}{\sqrt{\operatorname{var}(\xi) \operatorname{var}(\Delta)}} \in[-1,1],
$$

in which $\xi=\left(1,2,3, \ldots, n_{\text {cut }}\right), \Delta=\left(D_{c}(1), D_{c}(2), \ldots\right.$, $\left.D_{c}\left(n_{\text {cut }}\right)\right), n_{\text {cut }}=\operatorname{round}(N / 10)$, and the covariance and variance are defined with vectors $x, y$ of length $q$ as follows:

$$
\begin{aligned}
& \operatorname{cov}(x, y)=\frac{1}{q} \sum_{j=1}^{q}(x(j)-\bar{x})(y(j)-\bar{y}), \\
& \bar{x}=\frac{1}{q} \sum_{j=1}^{q} x(j), \quad \operatorname{var}(x)=\operatorname{cov}(x, x) .
\end{aligned}
$$

Step 6. Interpret outputs as follows.

(1) $K \approx 0$ indicates the underlying dynamics is regular (i.e., periodic or quasiperiodic), whereas $K \approx 1$ indicates the underlying dynamics is chaotic.

(2) Bounded trajectories in the $(p, s)$ plane imply the underlying dynamics is regular (i.e., periodic or quasiperiodic), whereas Brownian-like (unbounded) trajectories imply the underlying dynamics is chaotic.

\section{Some Basic Properties of the System (3)}

3.1. Symmetry and Invariance. Obviously, the four-dimensional system (3) has a natural symmetry about the coordinate plane $y-u$ since the coordinate transformation $(x, y, z$, $u) \rightarrow(-x, y,-z, u)$ satisfies the system is invariant for all values of the system parameters.

3.2. Dissipativity and the Existence of Attractor. From system (3), we obtain

$$
\begin{aligned}
\nabla V= & \frac{\partial\left(d^{q_{1}} x / d t^{q_{1}}\right)}{\partial x}+\frac{\partial\left(d^{q_{2}} y / d t^{q_{2}}\right)}{\partial y} \\
& +\frac{\partial\left(d^{q_{3}} z / d t^{q_{3}}\right)}{\partial z}+\frac{\partial\left(d^{q_{4}} u / d t^{q_{4}}\right)}{\partial u} \\
= & -(a+b+c),
\end{aligned}
$$

that is, the system (3) is dissipative with an exponential contraction rate $d V / d t=e^{-(a+b+c)}$ when $a+b+c>0$. In other words, the volume element $V(t)=V_{0} e^{-(a+b+c) t}$ for the initial volume $V_{0}$ means the trajectories of chaotic system (3) would converge ultimately onto an attractor as $t \rightarrow \infty$ with an exponential rate $(a+b+c)$.

\subsection{Equilibrium and Stability}

Theorem 7 (see [47]). Consider a nonlinear autonomous fractional order system as follows:

$$
\begin{gathered}
D^{q} x=F(X(t)), \\
X(0)=\left(x_{1}(0), x_{2}(0), \ldots, x_{n}(0)\right)^{T},
\end{gathered}
$$

where $X(t)=\left(x_{1}(t), x_{2}(t), \ldots, x_{n}(t)\right)^{T}, F(X(t))=\left(f_{1}(X(t))\right.$, $\left.f_{2}(X(t)), \ldots, f_{n}(X(t))\right)^{T}, q=\left(q_{1}, q_{2}, \ldots, q_{n}\right)^{T}$, and $0<q_{i}<1$ $(i=1,2, \ldots, n)$. If $A=D F_{(\widehat{X})}$ is the jacobian matrix at its equilibrium $\widehat{X}=\left(\widehat{x}_{1}, \widehat{x}_{2}, \ldots, \widehat{x}_{n}\right)^{T}$, then the point $\widehat{X}$ is asymptotically stable when $|\arg (\operatorname{eig}(\mathrm{A}))|>\mathrm{q}_{\mathrm{m}} \pi / 2$, where $q_{m}=\max _{1 \leq i \leq n}\left\{q_{i}\right\}$.

The equilibrium of the system (3) satisfies the following equations:

$$
\begin{gathered}
z+(y-a) x=0, \\
1-b y-x^{2}+u=0, \\
-x-c z=0, \\
d y=0 .
\end{gathered}
$$

By simple computation, one can obtain that system (3) has only one equilibrium point $E_{0}(0,0,0,-1)$.

Proposition 8. The equilibrium point $E_{0}$ is unstable.

Proof. For the equilibrium point $E_{0}$, the Jacobian matrix is

$$
J\left(E_{0}\right)=\left(\begin{array}{cccc}
-a & 0 & 1 & 0 \\
0 & -b & 0 & 1 \\
-1 & 0 & -c & 0 \\
0 & d & 0 & 0
\end{array}\right) .
$$

It is easy to get its eigenvalues corresponding to the equilibrium $J\left(E_{0}\right)$ as follows: $\lambda_{1}=-(1 / 2) b+(1 / 2) \sqrt{b^{2}+4 d}$, $\lambda_{2}=-(1 / 2) b-(1 / 2) \sqrt{b^{2}+4 d}, \lambda_{3}=-(1 / 2)(c+a)+(1 / 2)$ $\sqrt{(c-a)^{2}-4}$, and $\lambda_{4}=-(1 / 2)(c+a)-(1 / 2) \sqrt{(c-a)^{2}-4}$.

Obviously $\lambda_{1}>0$, that is, $\left|\arg \left(\lambda_{1}\right)\right|=0$, thus the equilibrium point $E_{0}$ is unstable based on Theorem 7 .

This proposition is proved.

\section{0-1 Test for Chaos in the System (3)}

In the next two subsections, some properties of the system (3) will be, respectively, discussed by varying investment incentive intensity $d$ and investment demand derivative $q_{2}$. The abovementioned Adams-Bashforth-Moulton predictorcorrector scheme and 0-1 test algorithm can be employed to get the desired numerical solutions of system (3).

4.1. Varying $d$ and Fixing $q_{1}=0.96, q_{2}=0.94, q_{3}=0.92, q_{4}=0.78$, $a=3, b=0.4$, and $c=0.4$. To simplify representation, one can fix $q_{1}=0.96, q_{2}=0.94, q_{3}=0.92, q_{4}=0.78, a=3, b=0.4$, and $c=0.4$ in this subsection. When the investment incentive intensity $d$ varies, the corresponding $K$ values are shown in Figure 1(a). The bifurcation diagram of interest rate $x$ with increasing the investment incentive intensity $d$ is presented in Figure 1(b). Obviously the bifurcation diagram well coincides with the $K$ diagram. The two abovementioned figures both show that system (3) changes gradually from chaos to stability as the investment incentive intensity $d$ grows larger. 


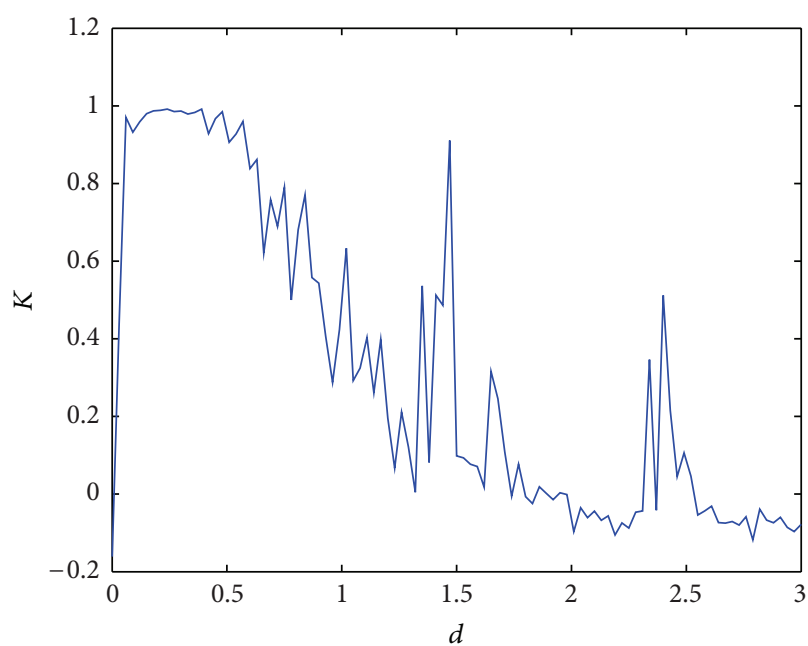

(a) 0-1 test with $K$ versus $d$

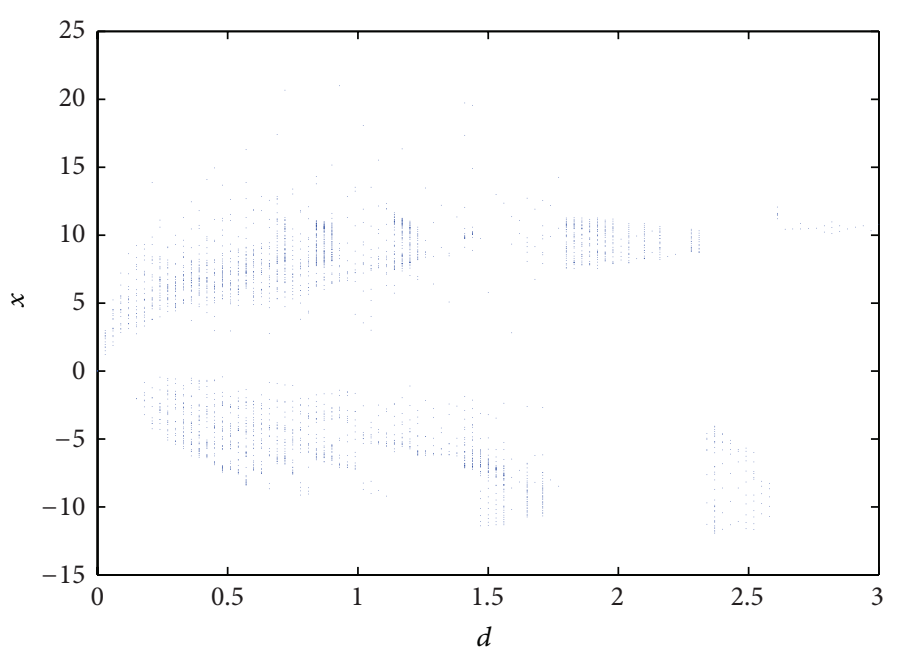

(b) Bifurcation with $d$ versus $x$

FIgURE 1: The evolvement of $K$ and $x$ versus $d$ with $q_{1}=0.96, q_{2}=0.94, q_{3}=0.92, q_{4}=0.78, a=3, b=0.4$, and $c=0.4$.

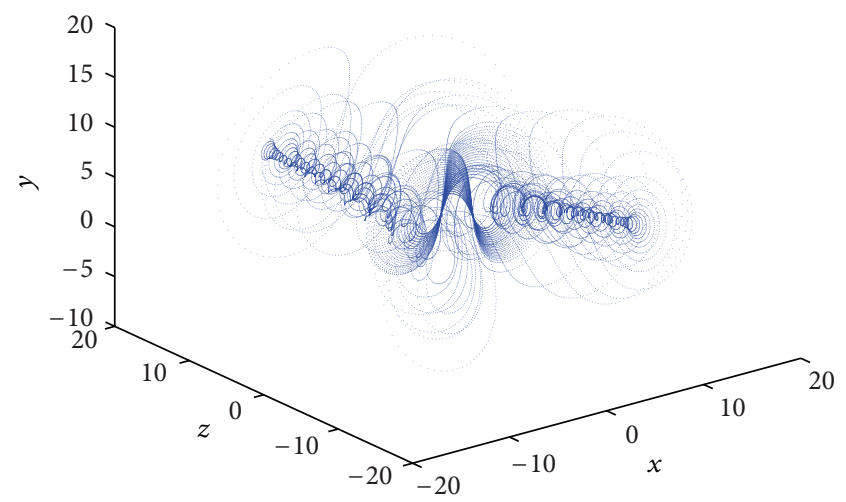

(a) Attractor in $x-y-z$ space

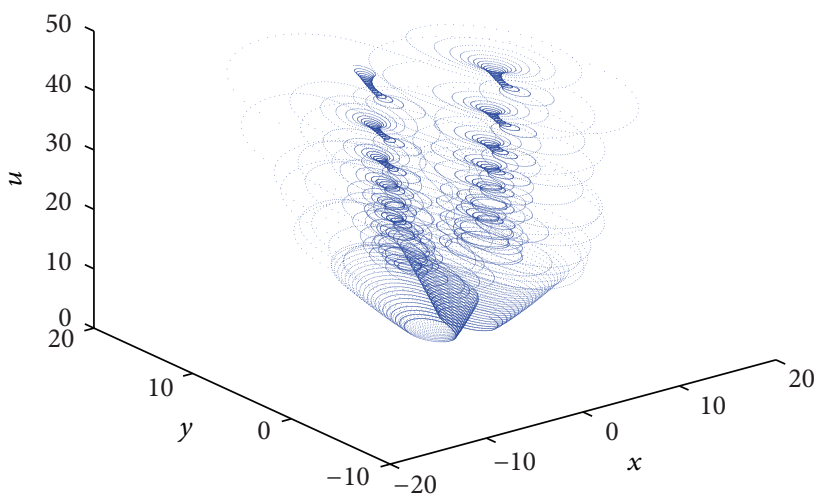

(b) $x-y$-u space

FIGURE 2: Phase portraits of system (3) with $q_{1}=0.96, q_{2}=0.94, q_{3}=0.92, q_{4}=0.78, a=3, b=0.4, c=0.4$, and $d=0.1$.

From Figure 1, the complex dynamical behavior of the system (3) can be clearly understood. When the investment incentive intensity $d$ is determined by its corresponding $K \approx$ 1 , the system (3) is chaotic. Whereas the investment incentive intensity $d$ is determined by its corresponding $K \approx 0$, the system (3) is regular.

Let me take two specific examples as illustrations in the system (3). When the investment incentive intensity $d=0.1$, its corresponding phase portraits are strange attractors as shown in Figure 2 and its trajectories in the new $(p, s)$-plane are Brownian-like as shown in Figure 3(a); that is, the system (3) is chaotic. Whereas the investment incentive intensity $d=2.8$, its corresponding phase portraits are quasiperiodic as shown in Figure 4 and its trajectories in the new $(p, s)$ plane are bounded as shown in Figure 3(b); that is, the system (3) is regular (quasiperiodic).

4.2. Varying $q_{2}$ and Fixing $q_{1}=0.98, q_{3}=0.97, q_{4}=0.78, a=3$, $b=0.4, c=0.4, d=0.1$. In the following subsection, $q_{1}=0.98$, $q_{3}=0.97, q_{4}=0.78, a=3, b=0.4, c=0.4, d=0.1$ are fixed. When $d$ varies, the corresponding $K$ values are shown in Figure 5(a). The bifurcation diagram of interest rate $x$ with increasing the investment demand derivative $q_{2}$ is given in Figure 5(b). Obviously the bifurcation diagram well coincides with the $K$ diagram, too. Figure 5 shows that the system (3) changes gradually from stability to chaos as the investment demand derivative $q_{2}$ grows larger.

From Figure 5 of the system (3), when the investment demand derivative $q_{2}$ is determined by its corresponding $K \approx$ 1 , the system (3) is chaotic. Whereas the investment demand derivative $q_{2}$ is determined by its corresponding $K \approx 0$, the system (3) is regular.

For example, in the system (3), when the investment demand derivative $q_{2}=0.4$, its corresponding phase portraits are quasiperiodic as shown in Figure 7 and its trajectories in the $(p, s)$ plane are bounded as shown in Figure 6(a); that is, the system (3) is regular (quasiperiodic). Whereas the investment demand derivative $q_{2}=0.89$, its corresponding phase 


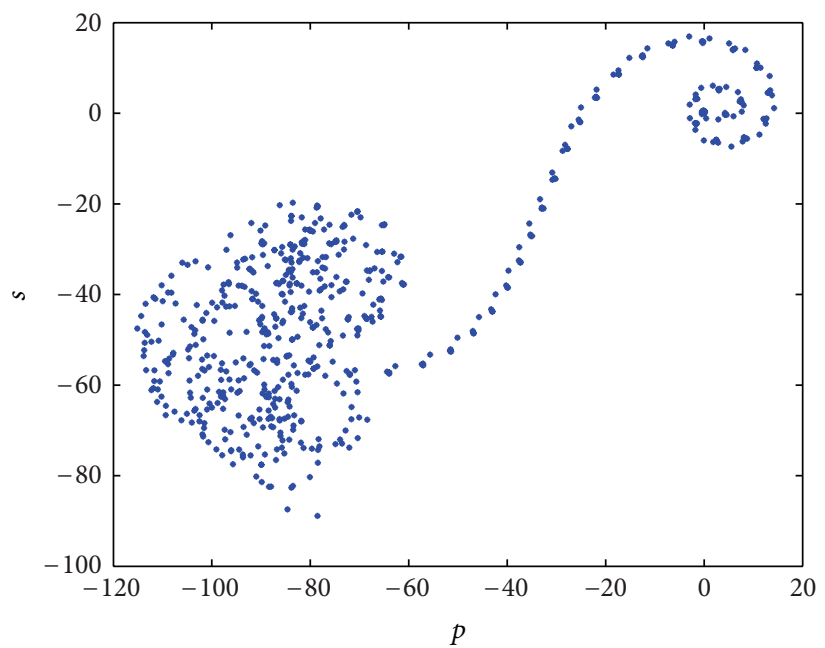

(a) $d=0.1$

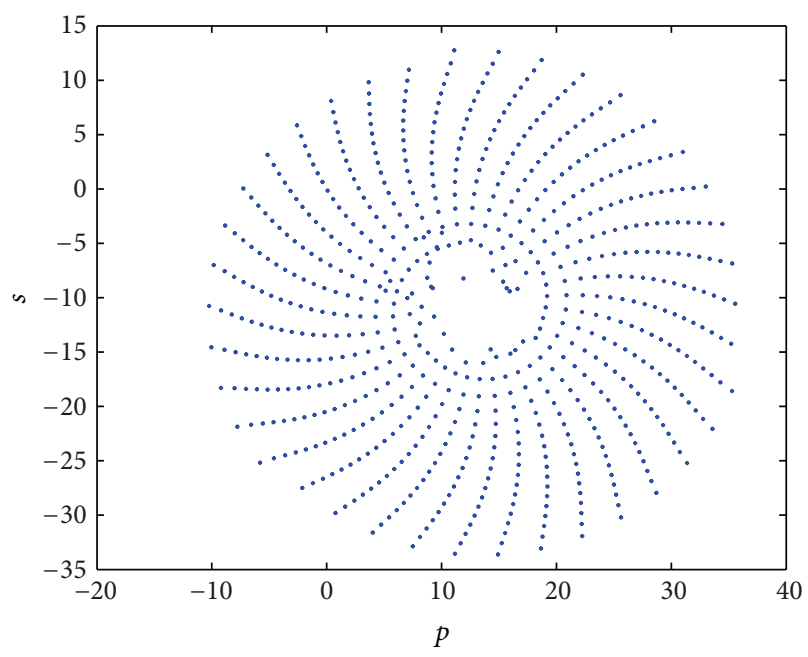

(b) $d=2.8$

FIGURE 3: Plots in new coordinates $(p, s)$ space with $q_{1}=0.96, q_{2}=0.94, q_{3}=0.92, q_{4}=0.78, a=3, b=0.4$, and $c=0.4$.

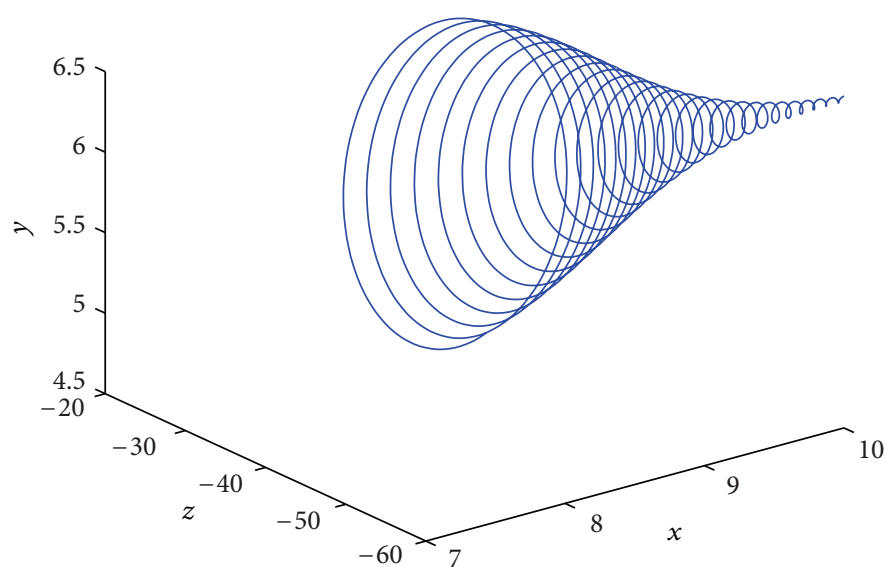

(a) $x-y-z$ space

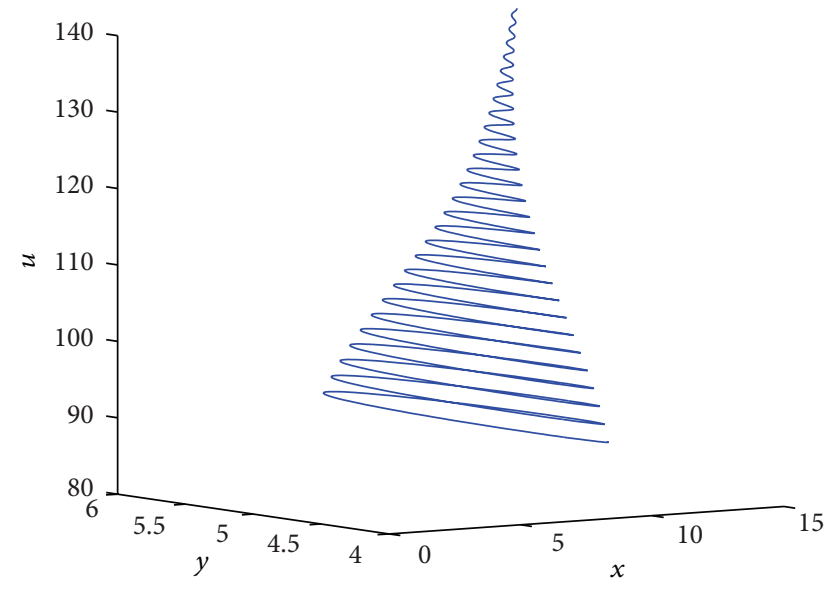

(b) $x-y-u$ space

FIgURE 4: Phase portraits of system (3) for $q_{1}=0.96, q_{2}=0.94, q_{3}=0.92, q_{4}=0.78, a=3, b=0.4, c=0.4$, and $d=2.8$.

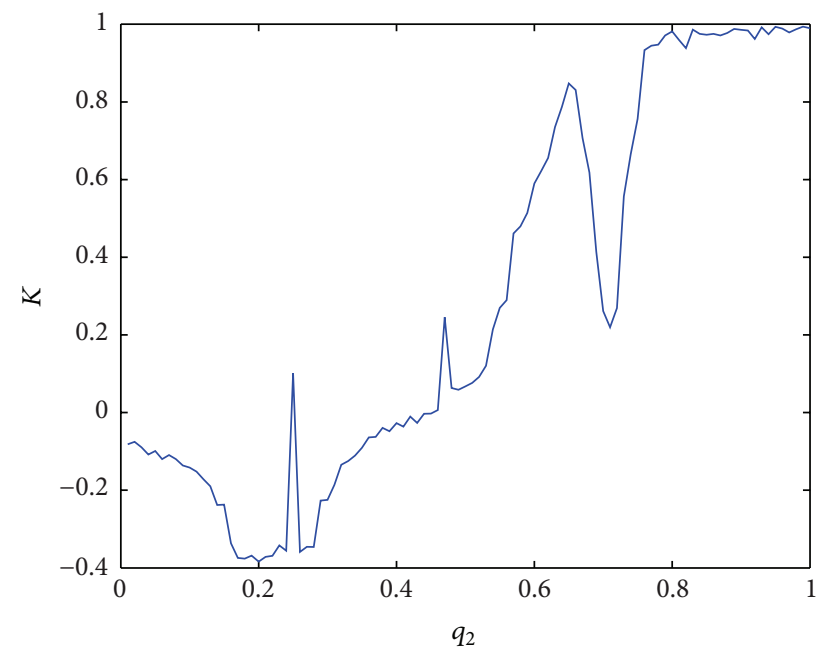

(a) 0 -1 test with $K$ versus $q_{2}$

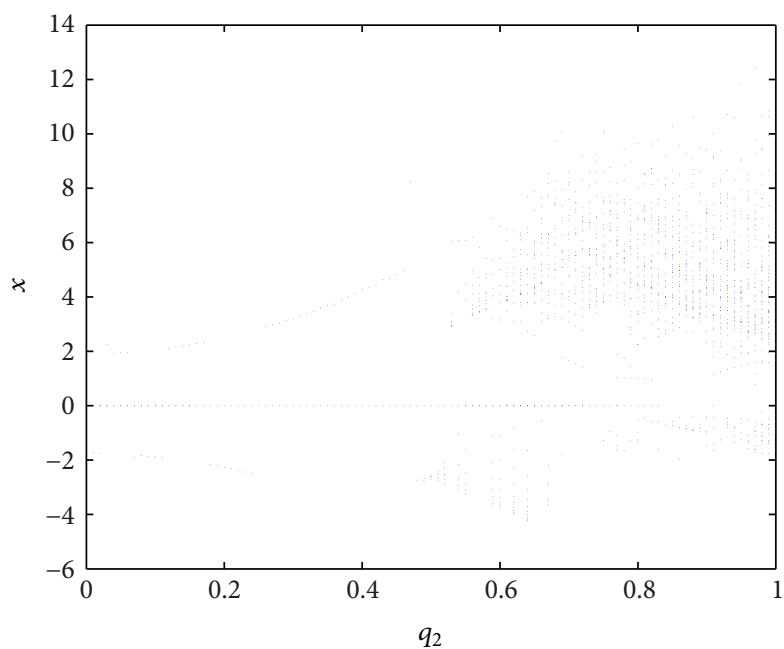

(b) Bifurcation with $q_{2}$ versus $x$

FIGURE 5: The evolvement of $K$ and $x$ versus $q_{2}$ with $q_{1}=0.98, q_{3}=0.97, q_{4}=0.78, a=3, b=0.4, c=0.4$, and $d=0.1$. 


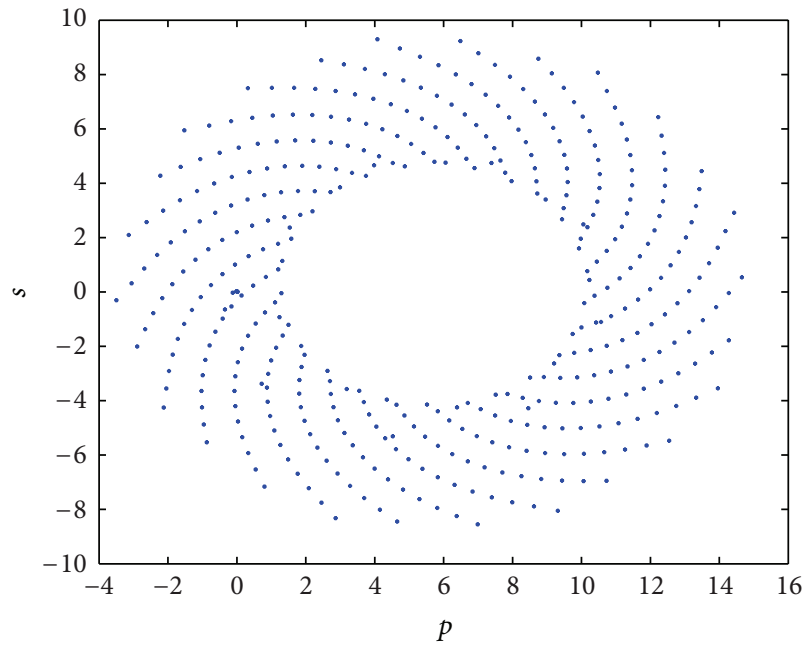

(a) $q_{2}=0.4$

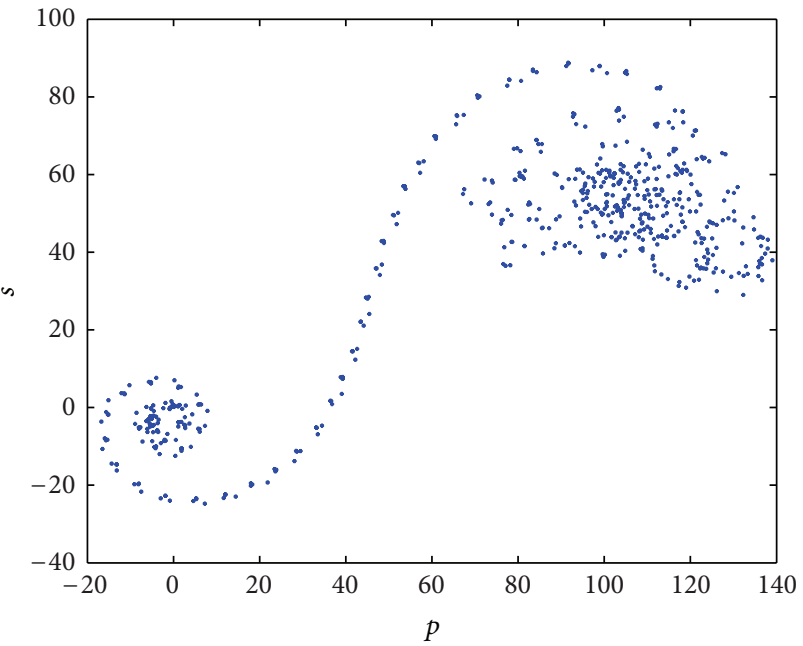

(b) $q_{2}=0.89$

FIgURE 6: Plots in new coordinates $(p, s)$ space with $q_{1}=0.98, q_{3}=0.97, q_{4}=0.78, a=3, b=0.4, c=0.4$, and $d=0.1$.

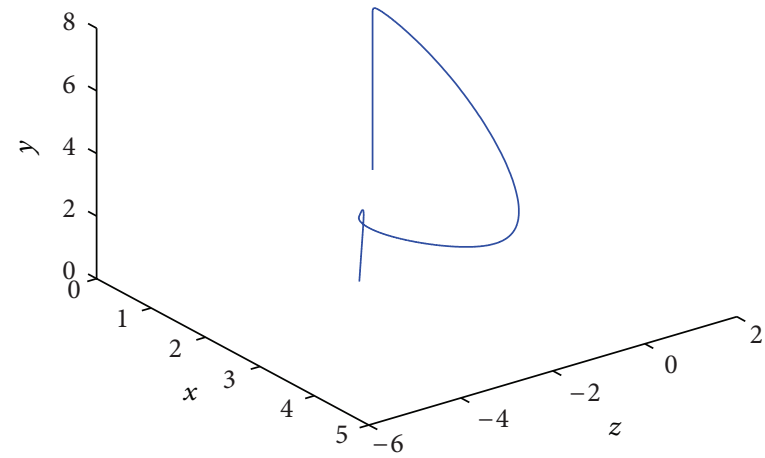

(a) $x-y-z$ space

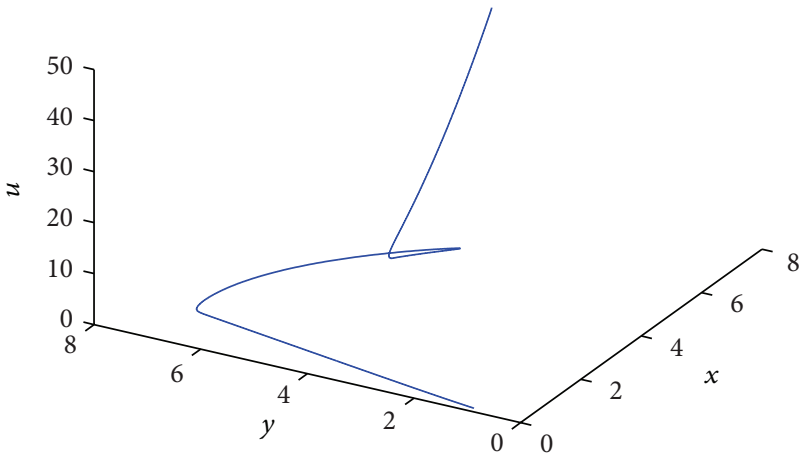

(b) $x-y$-u space

FIGURE 7: Phase portraits of system (3) for $q_{1}=0.98, q_{2}=0.4, q_{3}=0.97, q_{4}=0.78, a=3, b=0.3, c=0.8$, and $d=0.1$.

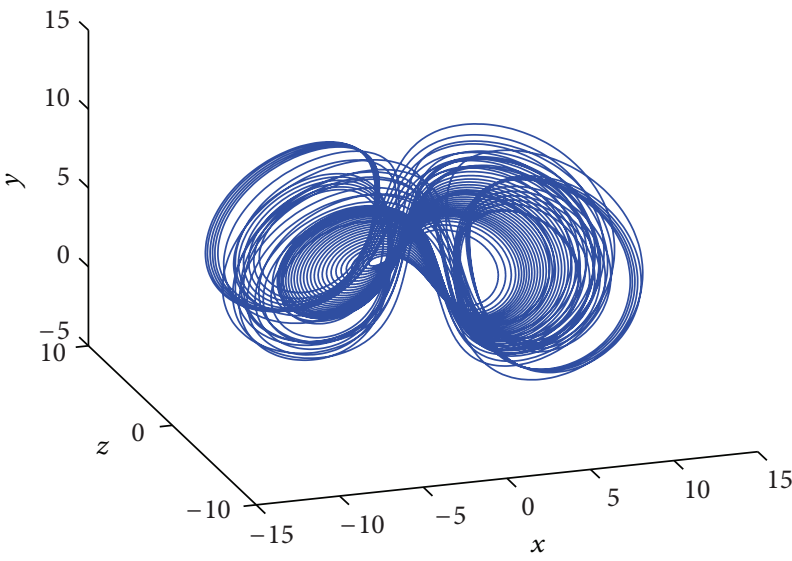

(a) $x-y-z$ space

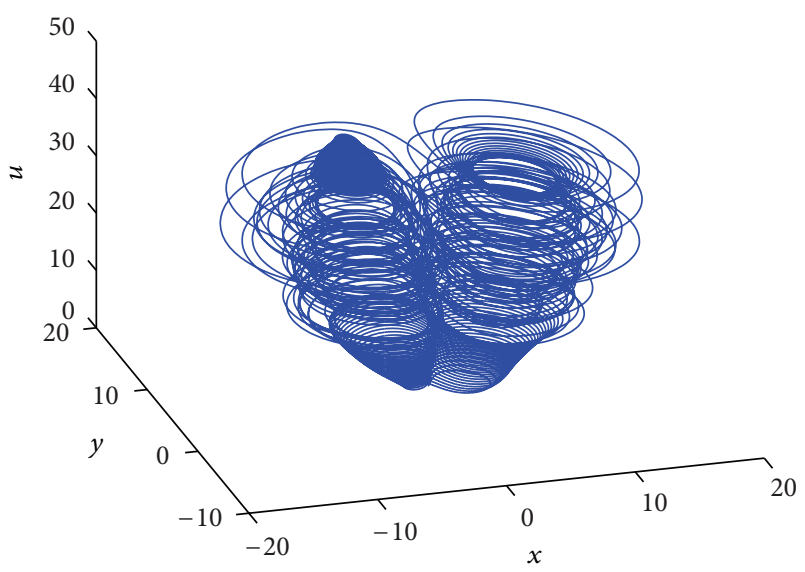

(b) $x-y-u$ space

FIGURE 8: Phase portraits of system (3) for $q_{1}=0.98, q_{2}=0.89, q_{3}=0.97, q_{4}=0.78, a=3, b=0.3, c=0.8$, and $d=0.1$. 
portraits are strange attractors as shown in Figure 8 and its trajectories in the $(p, s)$ plane are Brownian-like as shown in Figure 6(b); that is, the system (3) is chaotic.

\section{Conclusion}

A government is used to employing investment incentive to regulate financial systems. In this paper, a simple investment incentive is introduced into the classical chaotic financial system, and a 4-D chaotic financial system is obtained. What is more, there are some memory effects in the financial systems, so the 4-D fractional-order chaotic financial system is proposed by introducing the fractional calculus into the mentioned 4-D integer-order financial system. With the improved Adams-Bashforth-Moulton predictorcorrector scheme, phase portraits and bifurcation diagrams are illustrated, and then $K$ value diagram and Plots in new coordinates $(p, s)$ space are given by using the $0-1$ test algorithm. Thus chaotic dynamics is distinguished from regular dynamics in the 4-D fractional-order chaotic financial system by the abovementioned methods.

\section{Conflict of Interests}

The authors declare that there is no conflict of interests regarding the publication of this paper.

\section{Acknowledgments}

This work is supported partly by Excellent Young Scientist Foundation of Shandong Province (Grant no. BS2011SF018), National Social Science Foundation of China (Grant no. 12BJY103), Humanities and Social Sciences Foundation of the Ministry of Education of China (Grant no. 11YJCZH200), and National Natural Science Foundation of China (Grant no. 71272148).

\section{References}

[1] A. C.-L. Chian, E. L. Rempel, and C. Rogers, "Complex economic dynamics: chaotic saddle, crisis and intermittency," Chaos, Solitons and Fractals, vol. 29, no. 5, pp. 1194-1218, 2006.

[2] B. Xin, J. Ma, and Q. Gao, “The complexity of an investment competition dynamical model with imperfect information in a security market," Chaos, Solitons and Fractals, vol. 42, no. 4, pp. 2425-2438, 2009.

[3] D. Huang and H. Li, Theory and Method of the Nonlinear Economics, Sichuan University, Chengdu, China, 1993, (Chinese).

[4] J.-H. Ma and Y.-S. Chen, "Study for the bifurcation topological structure and the global complicated character of a kind of nonlinear finance system (I)," Applied Mathematics and Mechanics, vol. 22, no. 11, pp. 1240-1251, 2001.

[5] J.-H. Ma and Y.-S. Chen, "Study for the bifurcation topological structure and the global complicated character of a kind of nonlinear finance system (II)," Applied Mathematics and Mechanics, vol. 22, no. 12, pp. 1375-1382, 2001.

[6] J. Ma and T. Bangura, "Complexity analysis research of financial and economic system under the condition of three parameters change circumstances," Nonlinear Dynamics, vol. 70, pp. 23132326, 2012.

[7] Q. Gao and J. Ma, "Chaos and Hopf bifurcation of a finance system," Nonlinear Dynamics, vol. 58, no. 1-2, pp. 209-216, 2009.

[8] W.-C. Chen, "Nonlinear dynamics and chaos in a fractionalorder financial system," Chaos, Solitons and Fractals, vol. 36, no. 5, pp. 1305-1314, 2008.

[9] B.-G. Xin, T. Chen, and Y.-Q. Liu, "Complexity evolvement of a chaotic fractional-order financial system," Acta Physica Sinica, vol. 60, no. 4, Article ID 048901, 2011.

[10] M. S. Abd-Elouahab, N.-E. Hamri, and J. Wang, "Chaos control of a fractional-order financial system," Mathematical Problems in Engineering, vol. 2010, Article ID 270646, 18 pages, 2010.

[11] I. Pan, A. Korre, S. Das, and S. Durucan, "Chaos suppression in a fractional order financial system using intelligent regrouping PSO based fractional fuzzy control policy in the presence of fractional Gaussian noise," Nonlinear Dynamics, vol. 70, pp. 2445-2461, 2012.

[12] Z. Wang, X. Huang, and H. Shen, "Control of an uncertain fractional order economic system via adaptive sliding mode," Neurocomputing, vol. 83, pp. 83-88, 2012.

[13] G. Mircea, M. Neamtu, O. Bundau, and D. Opris, "Uncertain and stochastic financial models with multiple delays," International Journal of Bifurcation and Chaos, vol. 22, no. 6, Article ID 1250131, 19 pages, 2012.

[14] B. Xin, T. Chen, and J. Ma, "Neimark-sacker bifurcation in a discrete-time financial system," Discrete Dynamics in Nature and Society, vol. 2010, Article ID 405639, 12 pages, 2010.

[15] W.-C. Chen, "Dynamics and control of a financial system with time-delayed feedbacks," Chaos, Solitons and Fractals, vol. 37, no. 4, pp. 1198-1207, 2008.

[16] W.-S. Son and Y.-J. Park, "Delayed feedback on the dynamical model of a financial system," Chaos, Solitons and Fractals, vol. 44, no. 4-5, pp. 208-217, 2011.

[17] Y. Ding, W. Jiang, and H. Wang, "Hopf-pitchfork bifurcation and periodic phenomena in nonlinear financial system with delay," Chaos, Solitons \& Fractals, vol. 45, pp. 1048-1057, 2012.

[18] H. Yu, G. Cai, and Y. Li, "Dynamic analysis and control of a new hyperchaotic finance system," Chaos, Solitons \& Fractals, vol. 45, pp. 1048-1057, 2012.

[19] M. Dinica, "The real options attached to an investment project," Economia, Seria Management, vol. 14, pp. 511-518, 2011.

[20] B. Xin, T. Chen, and Y. Liu, "Synchronization of chaotic fractional-order WINDMI systems via linear state error feedback control," Mathematical Problems in Engineering, vol. 2010, Article ID 859685, 10 pages, 2010.

[21] B. Xin, T. Chen, and Y. Liu, "Projective synchronization of chaotic fractional-order energy resources demand-supply systems via linear control," Communications in Nonlinear Science and Numerical Simulation, vol. 16, no. 11, pp. 4479-4486, 2011.

[22] X. C. Li and W. Chen, "Nested meshes for numerical approximation of space fractional differential equations," The European Physical Journal, vol. 193, no. 1, pp. 221-228, 2011.

[23] X. Li and W. Chen, "Analytical study on the fractional anomalous diffusion in a half-plane," Journal of Physics A, vol. 43, no. 49, Article ID 495206, 2010.

[24] S. Chen and X. Jiang, "Analytical solutions to time-fractional partial differential equations in a two-dimensional multilayer annulus," Physica A, vol. 391, no. 15, pp. 3865-3874, 2012.

[25] X. Jiang and H. Qi, "Thermal wave model of bioheat transfer with modified Riemann-Liouville fractional derivative," Journal of Physics A, vol. 45, Article ID 485101, 2012. 
[26] W. Deng, "Numerical algorithm for the time fractional FokkerPlanck equation," Journal of Computational Physics, vol. 227, no. 2, pp. 1510-1522, 2007.

[27] W. Deng, "Smoothness and stability of the solutions for nonlinear fractional differential equations," Nonlinear Analysis: Theory, Methods and Applications, vol. 72, no. 3-4, pp. 1768-1777, 2010.

[28] K. Diethelm, N. J. Ford, and A. D. Freed, "Detailed error analysis for a fractional Adams method," Numerical Algorithms, vol. 36, no. 1, pp. 31-52, 2004.

[29] K. Diethelm, N. J. Ford, and A. D. Freed, "A predictor-corrector approach for the numerical solution of fractional differential equations," Nonlinear Dynamics, vol. 29, no. 1-4, pp. 3-22, 2002.

[30] G. A. Gottwald and I. Melbourne, "A new test for chaos in deterministic systems," Proceedings of the Royal Society A, vol. 460, no. 2042, pp. 603-611, 2004.

[31] G. A. Gottwald and I. Melbourne, "On the implementation of the 0-1 test for chaos," SIAM Journal on Applied Dynamical Systems, vol. 8, no. 1, pp. 129-145, 2009.

[32] G. A. Gottwald and I. Melbourne, "On the validity of the $0-1$ test for chaos," Nonlinearity, vol. 22, no. 6, pp. 1367-1382, 2009.

[33] I. Falconer, G. A. Gottwald, I. Melbourne, and K. Wormnes, "Application of the 0-1 test for chaos to experimental data," SIAM Journal on Applied Dynamical Systems, vol. 6, no. 2, pp. 395-402, 2007.

[34] S. Devi, S. Singh, and A. Sharma, "Deterministic dynamics of the magnetosphere: results of the 0-1 test," Nonlinear Processes in Geophysics, vol. 20, pp. 11-18, 2013.

[35] G. Litak, A. Syta, and M. Wiercigroch, "Identification of chaos in a cutting process by the 0-1 test," Chaos, Solitons and Fractals, vol. 40, no. 5, pp. 2095-2101, 2009.

[36] G. Litak, A. Syta, M. Budhraja, and L. M. Saha, "Detection of the chaotic behaviour of a bouncing ball by the 0-1 test," Chaos, Solitons and Fractals, vol. 42, no. 3, pp. 1511-1517, 2009.

[37] D. Bernardini, G. Rega, G. Litak, and A. Syta, "Identification of regular and chaotic isothermal trajectories of a shape memory oscillator using the 0-1 test," Journal of Multi-Body Dynamics K, vol. 227, no. 1, pp. 17-22, 2013.

[38] K. Sun, X. Liu, and C. Zhu, "The 0-1 test algorithm for chaos and its applications," Chinese Physics B, vol. 11, Article ID 110510, 2010.

[39] L.-G. Yuan and Q.-G. Yang, "A proof for the existence of chaos in diffusively coupled map lattices with open boundary conditions," Discrete Dynamics in Nature and Society, vol. 2011, Article ID 174376, 16 pages, 2011.

[40] K. Webel, "Chaos in German stock returns-new evidence from the 0-1 test," Economics Letters, vol. 115, no. 3, pp. 487-489, 2012.

[41] L. Zachilas and I. N. Psarianos, "Examining the chaotic behavior in dynamical systems by means of the 0-1 test," Journal of Applied Mathematics, vol. 2012, Article ID 681296, 14 pages, 2012.

[42] B. Xin and Y. Li, "Bifurcation and chaos in a price game of irrigation water in a coastal irrigation district," Discrete Dynamics in Nature and Society, vol. 2013, Article ID 408904, 10 pages, 2013.

[43] S. Vahedi and M. S. M. Noorani, "Analysis of a new quadratic 3D chaotic attractor," Abstract and Applied Analysis, vol. 2013, Article ID 540769, 7 pages, 2013.

[44] B. Krese and E. Govekar, "Nonlinear analysis of laser droplet generation by means of 0-1 test for chaos," Nonlinear Dynamics, vol. 67 , no. 3, pp. 2101-2109, 2012.
[45] Y. Kim, "Identification of dynamical states in stimulated Izhikevich neuron models by using a 0-1 test," Journal of the Korean Physical Society, vol. 57, no. 6, pp. 1363-1368, 2010.

[46] A. M. Fraser and H. L. Swinney, "Independent coordinates for strange attractors from mutual information," Physical Review A, vol. 33, no. 2, pp. 1134-1140, 1986.

[47] Y. Yu, H.-X. Li, S. Wang, and J. Yu, "Dynamic analysis of a fractional-order Lorenz chaotic system," Chaos, Solitons and Fractals, vol. 42, no. 2, pp. 1181-1189, 2009. 


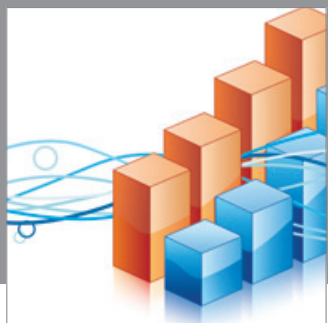

Advances in

Operations Research

mansans

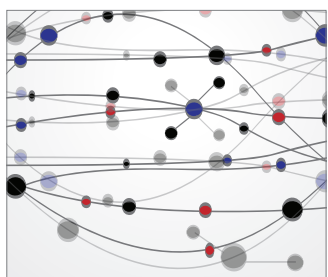

The Scientific World Journal
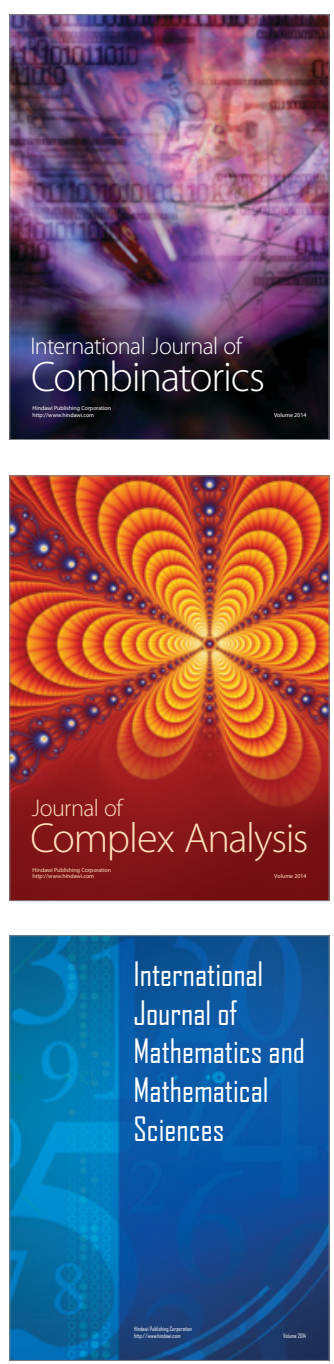
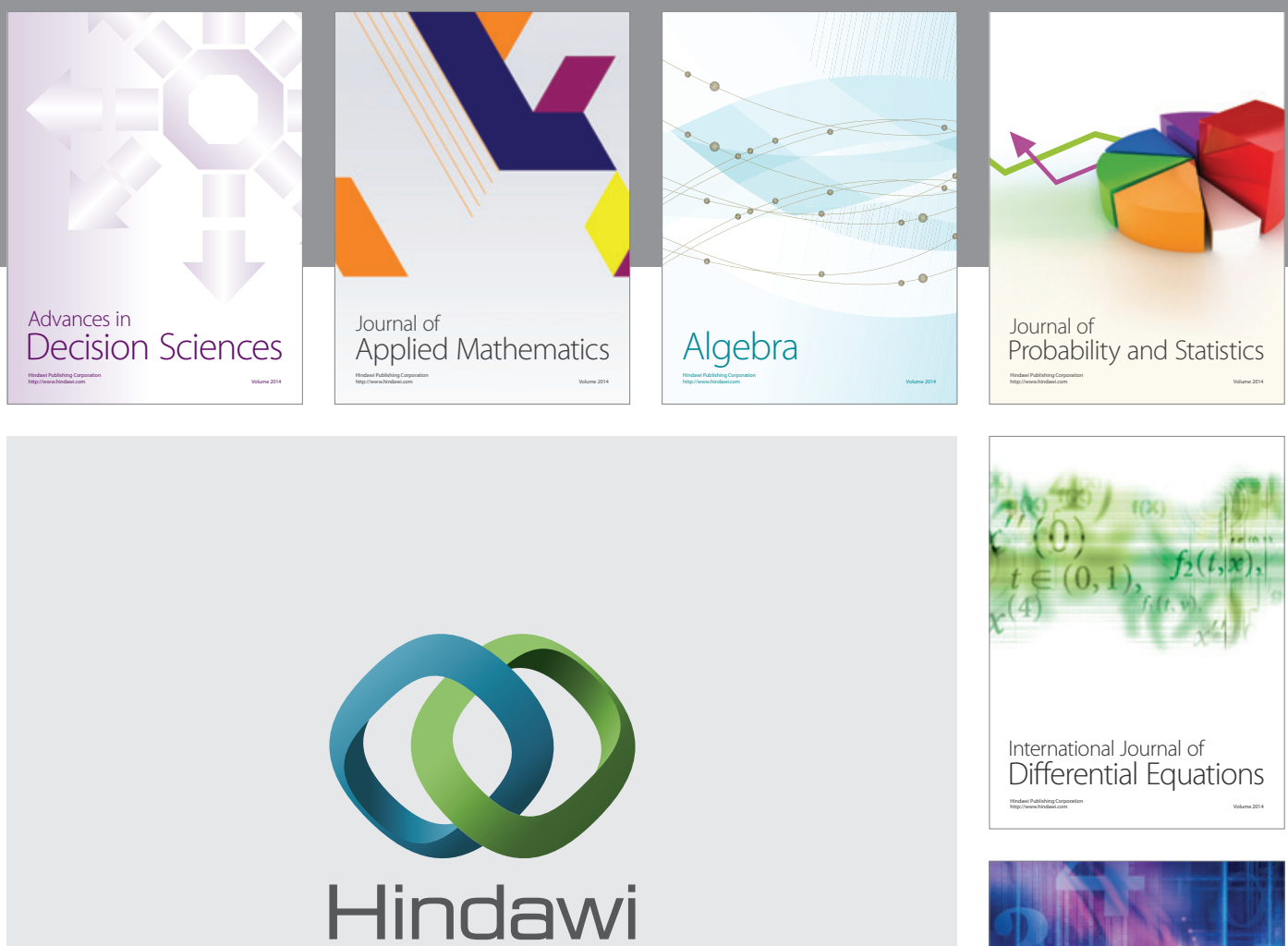

Submit your manuscripts at http://www.hindawi.com
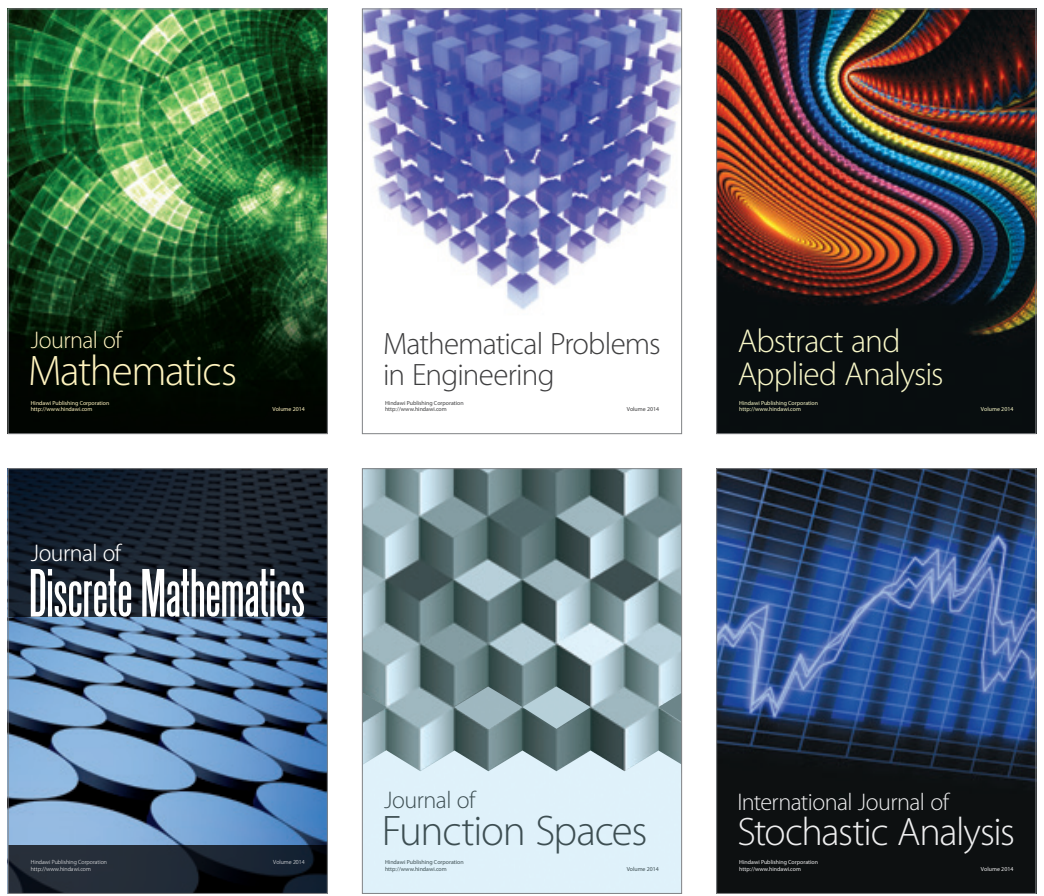

Journal of

Function Spaces

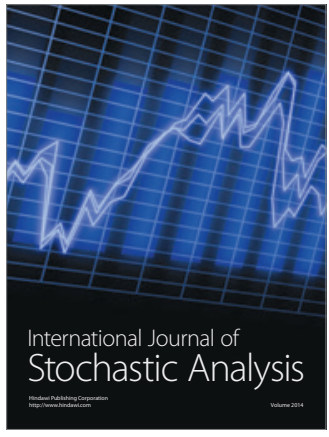

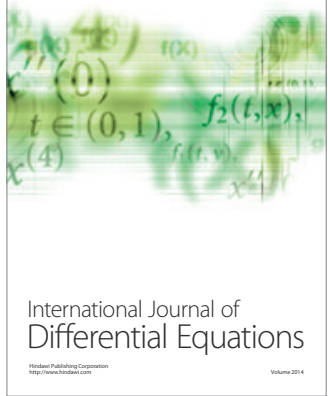
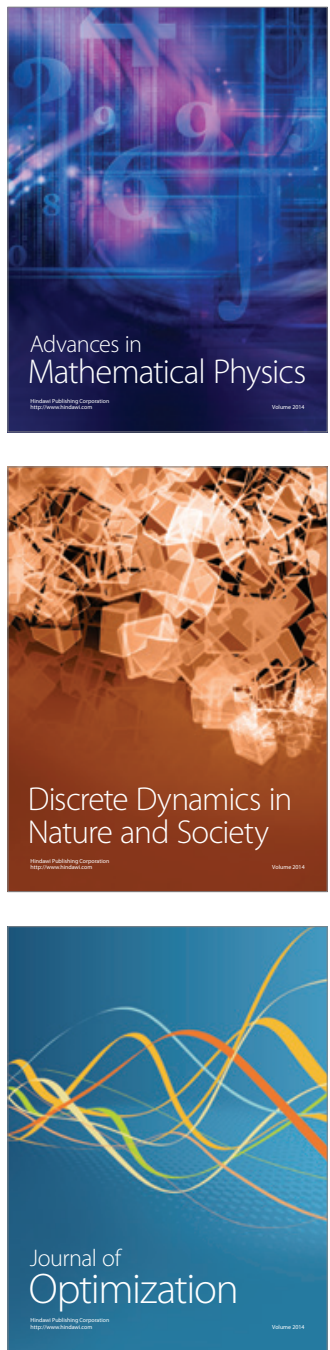